\title{
A Internet como veículo de comunicação publicitária
}

\section{Inłrodução}

MAIOR REDE DE computadores de todo o planeta, a Internet nasceu como plataforma de uso exclusivo de organizações governamentais, instituições de pesquisa e universidades. Mais tarde, o sucesso estrondoso de sua parte multimídia, a World Wide Web, despertou a atenção e o interesse das organizações comerciais, que tomaram de assalto a Web e impulsionaram sobremaneira o seu crescimento vertiginoso nos últimos anos.

A publicidade on-line manifestou-se, em sua primeira forma, nos próprios sites de empresas que marcavam sua presença na rede com o propósito de oferecer informações úteis a respeito de seus produtos e serviços, na maioria relacionados com Internet e informática. Outros formatos muito comuns são os pequenos anúncios eletrônicos conhecidos como banners e o patrocínio de seções dos provedores de acesso e de conteúdo.

Hoje, a publicidade cobre praticamente todos os serviços da rede, desde a Web até as mensagens de correio eletrônico. Este ensaio discorre sobre o surgimento da propaganda interativa na rede e examina a sua natureza em relação às mídias tradicionais com o objetivo de favorecer uma melhor compreensão da Internet como novo e emergente meio de comunicação publicitária.

J. B. Pinho

Professor da Universidade Federal de Viçosa

\section{- nascimento da publicidade on- line}

Muito antes da comercialização ser permitida na Internet, o serviço on-line norte-americano Prodigy testou a publicidade 
como uma fonte de receitas apenas entre os seus subscritores. Outros importantes serviços on-line, como CompuServe e America OnLine, mantiveram-se afastados da publicidade e somente vieram a vender patrocínios a partir de 1995. Vale lembrar que todos eles não fazem realmente parte da Internet, mas sim da Outernet, embora estejam conectados à Internet via gateways.

A World Wide Web tornou-se acessível ao público em 1993, ano em que foram abolidas as restrições para o uso comercial da Internet. Dale Dougherty lançou a primeira publicação comercial na Web, chamada GNN, uma espécie de revista eletrônica on-line. Em abril foi lançada a versão beta do primeiro programa gráfico de navegação, o Mosaic, permitindo aos seus usuários ver os textos e conteúdo gráfico da revista, bem como acessar outros sites pioneiros de publicidade - Mercury Center, Hotwired e Internet Shopping Network - que tiveram entre os seus primeiros anunciantes a Microsoft e o MCI.

A primeira tentativa de divulgação comercial massiva pela Internet ocorreu nos Estados Unidos, em 1994, e ficou mundialmente conhecida pela violenta reação que provocou entre os usuários e pela tremenda cobertura dada pela imprensa ao episódio. O escritório de advocacia Canter e Siegel imaginou uma maneira de usar a rede como um meio barato de comunicação e enviou um anúncio oferecendo seus serviços para a obtenção do green card para mais de 7 mil grupos de discussão.

Violando uma regra preciosa de etiqueta - a de não postar nos grupos de discussão material de natureza comercial -, a firma e o seu provedor de serviço receberam 30.000 flames em apenas 18 horas. $\mathrm{O}$ grande número de flames provocou sucessivos colapsos no provedor - 15 no total - e abalou seriamente a reputação do escritório de advocacia entre os membros da comunidade on-line.

A guerra de flames ocorreu pouco antes da revista Wired lançar o site HotWired (http://www.hotwired.com) com um modelo comercial de venda de publicidade. Temendo eventuais reações adversas, a Hotwired reduziu as dimensões pretendidas para o uso da publicidade e assim surgiu o banner, pequeno anúncio em forma gráfica, considerado hoje como o outdoor da superestrada da informação.

O primeiro contrato publicitário foi assinado com a AT\&T, no dia 15 de abril de 1994, sendo o site lançado no dia 27 de outubro de 1994. Entre os anunciantes pioneiros a veicularem seus banners no site Hot-Wired estavam ainda a IBM e a Zima, nova marca de bebida alcóolica da Pepsi. Zeff e Aronson (1997:17-18) revelam que, para surpresa da HotWired, ninguém criticou os anúncios, apenas se queixaram do fato de algumas páginas do site estarem ainda em construção. A cobertura da imprensa do lançamento do site também foi extremamente favorável e beneficiou os seus patrocinadores.

Ainda em 1994 surgem vários sites de diretórios e mecanismos de busca na Web, entre eles o Yahoo. Os usuários podiam então encontrar facilmente os sites de organizações comerciais e mesmo fazer suas compras em lojas listadas nas Páginas Amarelas. A atenção e o interesse das empresas foram despertados para as novas oportunidades oferecidas pelo novo meio, crescendo exponencialmente a presença dos sites comerciais na rede. Principalmente os vendedores on-line de computadores e softwares, de produtos especiais como vinho e flores, e de serviços como viagens.

A expansão dos anunciantes nos sites da Web resultou em queda nos preços praticados para a publicidade, embora ainda fossem comparativamente altos se considerado o retorno do investimento. No final de 1994, a Web passa a ser vista mais generalizadamente sob uma nova perspectiva: os seus usuários começaram a compreender que ela não era mais parte de uma rede exclusivamente acadêmica e filantrópica e, assim, seus produtos e serviços precisavam ser pagos. A cultura livre da Internet começou então a ser superada pelas empresas e seus interesses comerciais. 
Por volta de 1995, tornou-se cada vez mais aparente a necessidade da presença na Web para que uma empresa pudesse ser considerada moderna. Em vez de anunciar diretamente seus produtos e serviços, explica Sellers (1997:102), a empresa deveria anunciar na Web na firme esperança de que os internautas clicassem nos banners e links que os dirigissem então para o seu site, que receberia uma audiência de compradores qualificados.

Além disso, o banner tradicional - medindo cerca de $7,5 \mathrm{~cm} \times 2,5 \mathrm{~cm}$ e contendo uma mensagem curta e gráficos simples - não fornecia informação suficiente, o que estimulou ainda mais as empresas a terem seu site próprio na Internet. Por outro lado, provocou ainda o surgimento de novas formas e tipos de anúncios, bem como de sites mais interativos, que buscam estabelecer um maior relacionamento com o consumidor e ainda oferecer entretenimento e diversão para que os visitantes retornem ao site.

A tecnologia interativa de multimídia chegou à Web em 1995 e permitiu que os anúncios utilizassem animação, som e mesmo pequenos vídeos. As recentes tecnologias desenvolvidas para a Web - como Java, Active X, Virtual Reality Modeling Language - são altamente promissoras para que a publicidade cumpra, de maneira cada vez mais eficiente, o seu papel na construção de marcas e no estabelecimento de um relacionamento estável e duradouro com os consumidores e demais públicos-alvos.

\section{A Web e as mídias tradicionais}

A Web, a parte multimídia da Internet, apresenta inúmeras vantagens exclusivas em relação aos anúncios veiculados nos meios de comunicação tradicionais - televisão, rádio, cinema, jornal e revista. $\mathrm{O}$ exame de cada um destes veículos de comunicação publicitária permite identificar as diferenças entre eles e revelar a natureza interativa e instantânea da Web.

a) Televisão - Primeiro veículo em participação nas verbas de veiculação dos anunciantes do País, a TV detém cerca de $60 \%$ do mercado de publicidade e cobre 99,9\% dos municípios brasileiros. Sua versatilidade é grande, podendo ser empregada como mídia nacional, regional ou local, graças ao sistema de divisão de sinais das redes, por intermédio de suas afiliadas e repetidoras.

O consumo de TV no Brasil é bastante elevado, de 3 horas e meia diárias. Sua penetração é bastante significativa entre pessoas de ambos os sexos, das classes sociais A, B, C e D, e das faixas etárias de 15 a 65 anos.

A televisão é um veículo de grande audiência, impacto e força, pela sua capacidade de cobertura a curto prazo e a possibilidade do uso de comerciais com som, imagem, cores e movimento. Entretanto, a mídia começa a experimentar os efeitos da concorrência com a TV fechada para assinantes com programação especializada, especialmente nas classes sociais mais elevadas.

Os gêneros de programação mais apreciados pelos seus espectadores são o noticiário, novelas, documentários, programas de auditório e filmes. Assim, a TV é principalmente fonte de informação, de entretenimento e lazer, de prestação de serviços e de educação.

Apesar de todas as suas vantagens, os custos de produção e de inserção de comerciais na televisão são bastante elevados. Um simples comercial de 30 segundos em um programa no horário nobre chega a custar R\$ 50 mil, enquanto uma campanha publicitária pode custar milhões de reais.

b) Rádio - Veículo amplamente disseminado no Brasil, o rádio atinge $87,2 \%$ dos lares, que possuem mais de 2 aparelhos por domicílio. Presença constante na vida de todos - seja nas residências ou nos veículos que circulam pelas ruas e estradas -, o veículo tem uma programação que combina fundamentalmente lazer e entretenimento, informação e prestação de serviços.

O rádio recebe cerca de $9 \%$ dos in- 
vestimentos publicitários totais e apresenta dificuldades para sua atuação como mídia nacional, sendo difícil obter-se grandes coberturas em curto prazo utilizando as redes de emissoras, ao contrário do que acontece com a televisão. Esta limitação pode ser superada pela veiculação de comerciais em diversas estações, o que implica no aumento considerável de custos, apesar do seu baixo custo absoluto.

Portanto, o rádio vai constituir-se em uma excelente opção como mídia regional e local, em razão da grande quantidade de emissoras em operação no País, que resultam em considerável segmentação de seus ouvintes. Esta segmentação tem como principais fatores as condições geográficas da distribuição dos sinais e o conteúdo da programação do rádio.

Enquanto nas cidades menores uma emissora oferece uma grade de programação diversificada e dirigida a públicos diversos, nas capitais o rádio segmenta-se consideravelmente oferecendo uma programação única, como notícias ou músicas dos mais variados gêneros: jazz, clássica, popular brasileira, sertaneja, entre outros.

A publicidade radiofônica trabalha fundamentalmente com o som e a capacidade de imaginação dos seus ouvintes. As mensagens são transmitidas sob a forma de fonogramas - previamente gravados, com a denominação de spots para textos interpretados e de jingles para músicas cantadas - ou de textos falados pelos próprios locutores das emissoras, os quais podem se beneficiar do prestígio e da sua credibilidade perante os ouvintes.

c) Cinema - Pouco utilizado como veículo de comunicação publicitária, o cinema tem baixo alcance na população em geral, sendo seu público constituído majoritariamente de jovens de ambos os sexos, das classes A e B, com idade entre 15 e 29 anos. Restrições legais ainda limitam a apresentação dos comerciais apenas no início de cada sessão.

O cinema pode ser usado como mídia nacional, regional ou local, sendo a progra- mação montada pela compra cinema por cinema junto a empresas exibidoras. Em 1995, apenas 386 cinemas em todo o Brasil aceitavam veicular comerciais, estando 301 salas localizadas nas capitais de Estado.

As grandes vantagens do cinema residem no fato de oferecer um clima adequado para a veiculação de comerciais, já que ele atrai a atenção do espectador, pois não há nada que a desvie, e um alto impacto, graças às dimensões da tela, cor, imagens, sons e movimento.

d) Revista - As revistas absorvem cerca de $9 \%$ do total de investimentos publicitários no Brasil. Sua principal característica é a extrema seletividade dos leitores, provocada pelos muitos títulos voltados para os mais diversos segmentos da população - entre eles, as revistas infantis, atualidades e informação, femininas, de interesse geral, de turismo e lazer.

No caso das revistas técnicas, dirigidas e especializadas - vendidas em banca, por assinatura ou mesmo distribuídas gratuitamente -, as mais expressivas estão voltadas para economia e finanças, médicas, agropecuária, construção, indústrias em geral e transportes.

Os anúncios em revistas possibilitam, assim, o direcionamento preciso para muitos segmentos de consumidores e espaço para a abordagem mais profunda dos assuntos do interesse dos seus leitores. Muitas publicações apresentam uma excelente qualidade gráfica e permitem uma boa qualidade de reprodução das peças publicitárias, o que não acontece com os jornais.

A revista é considerada uma mídia nacional, mas existem títulos locais e regionais que constituem boas opções de mídia para campanhas localizadas. As grandes revistas também possibilitam veiculações de caráter regional, através de cadernos especiais e encartes publicitários com custos menores.

A penetração do meio chega a $91 \%$ entre a classe A e 72\% entre a B. A identificação do leitor com a revista que lê é muito grande, pois as pessoas compram os títulos de que tratam de assuntos de seu interes- 
se. Uma revista vai certamente ser lida por mais de uma pessoa, e mais de uma vez, durante certo tempo, o que determina que o meio tenha maior permanência entre os seus consumidores.

e) Jornal - Segunda mídia mais utilizada pelos anunciantes no Brasil, os jornais ficam com cerca de $25 \%$ dos investimentos totais em publicidade. Nos últimos anos, os grandes jornais beneficiaram-se com processos de produção informatizada e oferecem o recurso da cor para a veiculação de anúncios.

Entre outras características, o jornal é uma mídia de caráter local e regional. A cobertura nacional é bastante falha, pois o veículo concentra sua circulação na região ou Estado onde são publicados. Oferece ainda grande agilidade para a sua utilização, bom impacto entre as classes sociais mais altas e alta credibilidade para os anúncios, o que é decorrente de sua condição de mídia formadora de opinião.

Via de regra, os jornais brasileiros são dirigidos para o público em geral, oferecendo informação, prestação de serviços e lazer e entretenimento. Muitos deles adotaram a estrutura editorial de cadernos temáticos, em torno de assuntos como economia, política, esportes, cultura, feminino, infantil, entre outros. Alguns poucos títulos especializados estão voltados para os negócios e para outros segmentos mais ou menos homogêneos da população.

Embora disponham de grandes anunciantes nacionais, principalmente dos setores financeiro e automobilístico, os jornais veiculam significativa quantidade de anúncios de varejo, constituindo-se em excelente meio para a divulgação de promoções de âmbito local e regional. Os anúncios classificados, muito usados pela população em geral e empresas de todos os tamanhos, prestam um verdadeiro serviço de utilidade pública.

f) World Wide Web - Novo e emergente veículo de comunicação publicitária, a Web pode ser considerada relativamente pouco dispendiosa e rápida, transferindo a mensagem com som, cor e movimento, para qualquer parte do mundo, a uma fração do custo de muitas outras mídias.

A presença de grandes empresas na Web reflete a crescente importância desse novo meio e o reconhecimento dos seus benefícios para os negócios como um todo. Entretanto, os investimentos dos anunciantes brasileiros na publicidade on-line são ainda pouco expressivos - estimados pelo setor em US\$ 25 milhões nos últimos doze meses, representando apenas $0,25 \%$ do montante do mercado de propaganda.

O desenvolvimento do comércio eletrônico deve favorecer o crescimento da mídia on-line. A meta da Associação de Mídia Interativa (AMI) é atingir em 1999 valores entre US\$ 80 milhões e US\$ 100 milhões, que seriam equivalentes a cerca de $1 \%$ do total de investimentos publicitários. A gama de anunciantes deve também ser ampliada, já que hoje os grandes anunciantes da Web vêm do setor financeiro, seguidos pelas montadoras de automóveis e empresas de informática (cf. Deivisson, 1999: 48).

A publicidade na Internet apresenta uma dupla face. Embora a Web atinja enormes mercados nacionais e internacionais, condição para uma divulgação ampla e massiva, ela permite adicionalmente que esforços de publicidade sejam focados, com muita precisão, para segmentos de mercados específicos.

Entretanto, nenhuma outra mídia proporciona a grande vantagem da Web: a interatividade. A interação efetiva nos meios de comunicação tradicionais somente vai ser possível quando a TV (ou um controle especial) permitir que o telespectador toque na tela do aparelho para manifestar-se de alguma maneira a respeito do conteúdo que está sendo veiculado. Hoje, a única ação possível do consumidor é levantar-se e utilizar-se do telefone para contatar operadores de telemarketing que estão esperando por ele para a encomenda de um produto ou serviço anunciado.

$\mathrm{Na}$ Web, a interação com o consumidor potencial é instantânea. Permite que a 
empresa tenha um feedback da efetividade de sua publicidade on-line; permite saber imediatamente o que o visitante pensa sobre a mensagem e o produto e serviço que estão sendo anunciados; permite iniciar uma transação e receber o pedido do comprador diretamente no site.

Apesar de suas evidentes vantagens como meio de comunicação, a Internet não deve substituir os tradicionais instrumentos de comunicação publicitária. A própria história da evolução dos meios de comunicação tem mostrado que o surgimento de outro veículo não implica no inexorável desaparecimento do anterior.

\section{Nafureza da publicidade on-line}

A publicidade tem o propósito básico de disseminar informações para orientar o comportamento de compra e as preferências do consumidor para um determinado produto, serviço ou marca. Mas, na Web, a publicidade diferencia-se fundamentalmente dos outros meios por permitir que o consumidor possa interagir diretamente com o anúncio. Ele pode, então, clicar no anúncio para obter maiores informações ou mesmo realizar a compra do produto.

As características do novo meio de comunicação interativo conformam a sua natureza em termos das formas da presença da empresa na Web e dos benefícios que a publicidade on-line traz para os anunciantes e consumidores de produtos e serviços. Assim, a presença dos anunciantes na Web envolve uma decisão de escolha entre três opções de formato: sites de destinação, micro-sites e a realização eventual ou freqüente de campanhas de banners e patrocínio (cf. Doyle e outros, 1998).

Os sites de destinação combinam informação, entretenimento e recursos tecnológicos que agregam valor ao produto, serviço ou marca que está sendo divulgada na Web. Música, livros e softwares são os principais produtos que podem ser vendidos on-line e empregam sites de destinação para promover o conhecimento da marca, permitir a sua comparação com outros produtos similares e proporcionar serviços de pós-venda, como a assistência técnica.

As empresas que pretendem ter um canal pleno para a troca de informação com o consumidor devem estar cientes dos elevados custos de construção e manutenção dos sites de destinação. $O$ volume de interação não pode ser subestimado, pois muitas vezes vai exigir uma completa equipe de atendimento ao consumidor para não deixar sem resposta os correios eletrônicos recebidos.

Os sites de destinação não devem existir simplesmente. É preciso divulgar o seu endereço de todas as formas possíveis e reservar uma dotação orçamentária para este fim, estimada em no mínimo $20 \%$ dos gastos totais com a comunicação interativa.

Os micro-sites, como o próprio nome indica, são de menor tamanho e podem ser hospedados em provedores de conteúdo ou redes. Eles permitem comunicar os benefícios do produto e reunir informação acerca do consumidor, sem os custos dos sites de destinação. $\mathrm{O}$ anunciante deve deixar claro aos navegantes que a página é tipicamente de propaganda, pois o conteúdo comercial mascarado como editorial pode abalar a confiança na marca.

Os anunciantes de produtos de compra comparada - como roupas, aparelhos domésticos e móveis - devem ter o cuidado de colocar as páginas do seu micro-site onde está o seu consumidor ou prospect. A Levi's, por exemplo, realizou investimentos consideráveis para colocar micro-sites em todos os principais sites dirigidos aos jovens.

Os banners devem também ser interativos, permitindo aos usuários solicitar amostras grátis, registrar-se para participar de um concurso ou concorrer a prêmios e encomendar o produto. As empresas de produtos de consumo devem incrementar suas vendas com o emprego de banners em campanhas criativas e manter seus sites corporativos para propósito como manter relações com investidores, fornecedores e o recrutamento de pessoal. 
Qualquer patrocínio que venha a ser cogitado pela empresa deve ser feito observando que o conteúdo seja apropriado e diretamente relacionado com os seus negócios. Um banco, por exemplo, tem muito a ganhar com a figuração do seu patrocínio na seção de economia do site de um jornal ou de um diretório de grande tráfego.

Agora levando em conta a natureza e as características próprias da publicidade on-line, Zeff e Aronson (1997:13-14) enumeraram suas cinco grandes vantagens exclusivas: dirigibilidade, rastreamento, acessibilidade, flexibilidade e interatividade.

a) Dirigibilidade - A Web propicia aos anunciantes uma ampla gama de possibilidades para dirigir suas mensagens a alvos específicos. Uma campanha pode voltar seu foco para os consumidores ou prospects de uma determinada empresa, código de CEP, regiões geográficas e nações, bem como hora do dia, plataforma de computador e browser. Embora a Web ainda não permita precisar targets com base em características demográficas, a publicidade on-line pode trabalhar tendo como referência as eventuais preferências demonstradas pelos usuários, o que nenhum outro veículo consegue fazer.

b) Rastreamento - Os sites permitem rastrear o modo como os usuários interagem com suas marcas e localizar o que é do interesse dos consumidores e prospects. Um fabricante de carros, por exemplo, pode descobrir como o visitante navega pelo seu site e identificar em que tipo de informação ele está mais interessado: desempenho do automóvel, especificações de segurança ou os opcionais que acompanham um determinado modelo.

A audiência de um site pode ser medida pela contagem dos visitantes que o acessam, enquanto a resposta a um anúncio pode ser verificada pelo número de vezes que o banner é clicado pelos usuários.

c) Acessibilidade - A publicidade online está disponível ao acesso dos usuários
24 horas por dia, 7 dias por semana, 365 dias por ano.

d) Flexibilidade - A flexibilidade da publicidade on-line é total, pois uma campanha pode ser lançada, atualizada ou cancelada imediatamente. No período de uma semana, o progresso da campanha pode ser acompanhado e, se necessário, é possível alterá-la na semana seguinte, geralmente sem importar em custos elevados e mesmo proibitivos de produção, como no caso da televisão.

e) Interatividade - O objetivo da publicidade é engajar e envolver o prospect com a marca ou produto. A Web permite alcançar o objetivo com maior efetividade, porque o consumidor pode interagir com o produto, testá-lo e, se escolhido, comprá-lo imediatamente. Um software, por exemplo, pode ter uma versão de demonstração para teste imediato; uma vez finalizado o exame e ele se mostrar de agrado do consumidor, a compra pode ser efetivada na mesma hora.

A Web é, portanto, um eficiente canal de publicidade cujas vantagens não são exclusivas dos anunciantes. Por seu lado, os consumidores podem usufruir de vários benefícios, sendo o primeiro - e o mais evidente - o acesso a uma grande quantidade de informações oferecida de maneira altamente dinâmica pela natureza interativa do meio e pelo ambiente em hipertexto, permitindo a pesquisa de forma não-linear, que auxilia e mesmo facilita o processo de decisão de compra.

O segundo benefício proporcionado ao consumidor consiste na facilidade do levantamento, análise e controle de dados a respeito de produtos e serviços, que permitem a compra por comparação e a experimentação de produtos on-line pelo usuário.

A redução de preços é o terceiro benefício, como decorrência da competição entre os vários fornecedores presentes na rede, o que resulta ainda em melhor qualidade e 


\section{maior variedade de itens .}

\section{Notas}

BARRETT, Neil. Advertising on the Internet: how to get your message across on the World Wide Web. London: Kogan Page, 1997.

DEIVISSON, Daniel. "Muito além do banner". Internet Business, Rio de Janeiro, ano 2, n. ${ }^{0}$ 17, jan. 1999, p.48-50.

DOWLING JR., Paul J. e outros Web advertising and marketing. 2nd. ed. Rocklin: Prima, 1998.

McCANN-ERICKSON BRASIL. Media Brazil by McCann 19951996. São Paulo: McCann-Erickson Brasil, 1997.

O'KEEFE, Steve. Publicity on the Internet: creating successful publicity campaigns on the Internet and the commercial online services. New York: John Wiley \& Sons, 1997.

SAMPAIO, Rafael. Propaganda de A a Z; como usar a propaganda para construir marcas e empresas de sucesso. 5. ed. Rio de Janeiro: Campus, ABP, 1997.

SELLERS, Don. Getting hits: the definitive guide to promoting your website. Berkeley: Peachpit Press, 1997.

SHIVA, V. A. The Internet publicity guide: how to maximize your marketing and promotion in cyberspace. New York: Allworth Press, 1997.

ZEFF, Robbin and ARONSON, Brad. Advertising on the Internet. New York: John Wiley \& Sons, 1997. 